\title{
Los horizontes epistemológicos de la biografía*
}

\author{
Os horizontes epistemológicos da biografia \\ The epistemological horizons of biography \\ Anna Caballé \\ Universidad de Barcelona, Barcelona, España
}

Resumen: El artículo reflexiona sobre los patrones de la objetividad en los que se mueve la escritura biográfica contemporánea. Apoyándose en Thomas Khun distingue entre aquellos construidos a partir del conocimiento directo del biografiado de los que parten de una aproximación indirecta, bien por la falta de sincronía en los tiempos de biógrafo y biografiado, bien porque se parte de una voluntad previa de distanciamiento. De las condiciones generales el artículo pasa a reflexionar sobre la evolución de la biografía en España y sus condiciones de evolución hasta el presente.

Palabras clave: Biografía; Canon biográfico; Cultura española; Epistemología

Resumo: $\mathrm{O}$ artigo reflete sobre os padrões de objetividade nos quais se move a escrita biografia contemporânea. Apoiando-se em Thomas Khun, distingue os padrões construídos a partir do conhecimento direto do biografado daqueles que partem de uma aproximação indireta, seja por falta de sincronia entre os tempos do biógrafo e do biografado, seja porque parte de uma vontade prévia de distanciamento. Das condições gerais, o artigo passa a refletir sobre a evolução da biografia na Espanha e suas condições de evolução até o presente.

Palavras-chave: Biografia; Cânone biográfico; Cultura espanhola; Epistemologia

\begin{abstract}
The article reflects on the patterns of objectivity in which contemporary biographical writing moves. Relying on Thomas Khun distinguishes between those built from the direct knowledge of the biography of those who start from an indirect approach, either by the lack of synchrony in the times of biographer and biographed, or because part of a prior will of distancing. From the general conditions, the article begins to reflect on the evolution of the biography in Spain and its conditions of evolution up to the present.
\end{abstract}

Keywords: Biography; Biografic canon; Spanish culture; Epistemology

\begin{abstract}
¿Habría alguna forma literaria cabal para expresar la convicción de que toda la historia se compone de intentos aislados y fallidos, mal cosidos luego a la fuerza por quien se los encuentra ahí amontonados a su espalda y los quiere justificar y ordenar de alguna manera para que tanta ruina no le ahogue?

(Carta de Carmen Martín Gaite a Juan Benet, Madrid, 6 de mayo de 1966)
\end{abstract}

\footnotetext{
* El artículo se ha escrito en el marco del proyecto financiado por la Agencia Estatal de Investigación y por el Fondo Europeo de Desarrollo Regional: "La razón biográfica: biografias y narraciones autobiográficas en la investigación histórica y literaria del siglo XX europeo. Estudios de caso y reflexión teórica". HAR2017-82500-P (AEI/FEDER/UE).
} 


\section{1}

La reflexión de la escritora vallisoletana Carmen Martín Gaite dirigida a su amigo Benet tiene que ver en primer lugar con el tiempo y la ruina, pero de forma más inmediata con el laborioso proceso de escritura de su biografía sobre el político y escritor Melchor de Macanaz ${ }^{1}$, un hombre ambicioso, partidario de la dinastía borbónica en la Guerra de Sucesión española, pero de poca fortuna. Acabó sus días preso en el castillo de San Antón de A Coruña. Dejó muchos escritos sin publicar y Martín Gaite, hasta entonces dedicada al género novelesco, se enfrentó a un ingente material inédito, material de sobra para emprender un trabajo sobre el personaje. Pero la pregunta que se formulaba la escritora una y otra vez era ¿qué tipo de trabajo quiero hacer con todo ello? La decisión, antes no dio con un guión claro y seguro de su propósito, le llevaría años y Juan Benet serviría de interlocutor intelectual al que la escritora volcaría sus dudas y dificultades en un intercambio de ideas y opiniones sobre la biografía del mayor interés ${ }^{2}$. Este respondería con sus propias reflexiones y, en conjunto, su correspondencia analiza muy bien el proceso de escritura biográfica. Benet responde a su amiga:

Se diría que del Archivo Histórico tratas de sacar el material para dar cuenta cabal de un individuo. Dar cuenta cabal en el sentido de poder asumir su libertad para saber que allí había una inquietud, una pasión $o$ un desengaño aun cuando no haya improntas que las pongan de manifiesto. Al intento de penetrar en cierta intimidad suya el difunto opone una resistencia tenaz y se rodea de un muro infranqueable contra el que cualquier croquis resulta infructuoso. El difunto se aparece como una ciudad amurallada al sitiador; a unos pasos de ella y rodeándola por todas partes apenas la conoce sino por unas torrecillas, unos tejados, unos reflejos de la luz en sus cristales (Martín Gaite/Juan Benet, 2011, p. 115).

Un pasaje precioso que parte de la dificultad de levantar el edificio de una vida humana a partir de unas pocas huellas disponibles. Una tortura para la novelista, acostumbrada a entrar a saco en cualquier intimidad (y pienso en su novela Entre visillos, por ejemplo), enfrentarse a una situación ante la que sus avances sobre Macanaz dependían de los documentos y escritos, a menudo contradictorios entre sí, que iba localizando del personaje.

\footnotetext{
1 El libro se titularía El Proceso de Macanaz. Historia de un empapelamiento, Espasa Calpe, 1999.

2 Carmen Martín Gaite/Juan Benet. Correspondencia, José Teruel (ed.),
} Galaxia Gutenberg, 2011.
Y seguiré con otra cita, tan sugerente como las dos anteriores. Pertenece a otra novelista, Patricia Highsmith, igualmente obsesionada en la comprensión de la existencia humana y dice así:

\begin{abstract}
Si nos dejaran pasar un cuarto de hora en el estudio de Shakespeare en 1605 , cómo observaríamos cada uno de sus movimientos, con qué avidez nos fijaríamos en cómo levanta la cabeza, cómo toca el borde del papel con la mano, en el ángulo que forma su espalda cuando escribe. Qué poco sabemos de la historia. El tiempo es una columna de monóxido de carbono cuyo extremo se va deshilachando como el final de una cuerda vieja y va cayendo en el olvido.
\end{abstract}

La maravillosa observación fue escrita por Highsmith en su Diario el 12 de diciembre de $1941^{3}$. Tenía 20 años y está claro que una parte de la anotación refleja la intensa pasión que, de joven, la escritora estadounidense sentía, no tanto por la obra como por la personalidad de otros escritores de los que ella quería saber más, probablemente quería saberlo todo. Pasión que la llevaba a sentir nostalgia de una escena imposible: poder observar cómo trabajaba Shakespeare reparando en los detalles aparentemente menos sustanciales: la forma en que encorvaba la espalda al escribir, por ejemplo. Una escena sobre la que tan sólo puede especularse. Sin duda debió de producirse, no cabe la menor duda, pero nos es imposible recuperarla. En todo caso, más interesante es todavía la segunda parte de su anotación, la forma en que la novelista concibe el tiempo como una columna de monóxido de carbono. En palabras menos aceradas, la imagen había sido utilizada ya por Stefan Zweig en su biografía de Fouché (1929), escrita en la plenitud de su talento, cuando subraya que la muerte en 1820, del que fuera el temible jefe de la policía durante el periodo revolucionario y también napoleónico , despertó tan solo una ligera curiosidad en la sociedad francesa porque ya sobre su nombre había empezado a avanzar el olvido: "Únicamente un humo delgado y pálido de recuerdo se levanta fugazmente de su nombre extinguido y se deshace, casi sin dejar rastro, en el cielo apacible del tiempo". Zweig en 1929 ve todavía el tiempo como un cielo apacible en el cual se difumina la voluta de humo que es el recuerdo, mientras que Highsmith, con su extremada conciencia del detalle, apunta el carácter destructor, corrosivo, de esa columna de humo que va a caer en el vacío y por tanto en el olvido. Ningún cielo apacible acoge la memoria humana, sometida a los vaivenes de los cambios y las mentalidades, sometida a la incontenible pérdida de la existencia y a su destrucción imparable. Lo que para una generación fue admirable

\footnotetext{
3 Cfr. The Talented Miss Highsmith, de Joan Shenkar, 2009. Traducida al castellano por Clara Ministral, Circe, 2010, p. 17.
} 
estímulo humanístico, en las siguientes sufriría el contraste del análisis implacable, incluso demoledor, fruto de la conciencia de vacío que rodea a la vida humana.

En otras palabras, el tiempo no es el "gran escultor" que dijera Marguerite Yourcenar", sino un carburo tóxico que pulveriza a sus criaturas arrastrándolas a la nada. La tendencia es esta y todos sabemos que sin un esfuerzo positivo, hoy diríamos proactivo, por preservar su recuerdo, poco queda de una vida humana después de la tercera generación. Los dos escritores, Zweig y Highsmith, sin embargo, comparten el carácter evanescente de la existencia. Y la dificultad de fijar un cierto tipo de conocimiento sobre ella antes de su evaporación total. Imposible atraparla en su maravillosa plenitud cotidiana, nos conformaríamos con atrapar al vuelo el preciso detalle de un gesto, una escena, una conversación, un paseo. A los biógrafos nos encantaría poder emprender ese viaje en el tiempo y comprender desde dentro los enlaces que encadena la experiencia de nuestro biografiado, las fuentes de sus placeres y displaceres, una simple imagen en movimiento.

En todo caso, la escena imaginaria con la que especula Highsmith sobre Shakespeare contiene o intuye los dos grandes patrones de objetividad sobre los que se asienta la biografía, en el sentido que le da a este concepto Thomas Khun en La estructura de las revoluciones cientificas (1962). Un patrón de objetividad es un modelo que permite definir una tradición de investigación particular y coherente. Pues bien, uno de esos patrones de objetividad en la biografía no incluye el conocimiento directo del objeto (entendiendo por objeto el sujeto biografiado, según la diferencia establecida por la filosofía en cuanto al mecanismo del conocimiento entre dos entidades: el que conoce o cognoscente llamado sujeto y la cosa conocida llamada objeto), bien porque es un personaje del pasado, porque ya ha fallecido o bien porque el biógrafo prefiere asegurarse la autonomía de su investigación manteniéndose a distancia. Hay una forma de operar relativamente afín entre cualquiera de los biógrafos de Cervantes y el autor de una biografía actual que no ha querido contar con el trato directo de su biografiado a fin de asegurarse la libertad que requería su trabajo. Claro que cuando la época de biógrafo y biografiado es coincidente (ocurre en la mayoría de biografías de políticos) se dispone de un conocimiento si no directo del personaje, al menos osmótico del mismo que facilita grandemente la tarea. Mientras que un biógrafo de Cervantes debe

\footnotetext{
4 El tiempo, gran escultor (ALFAGUARA, 1989, trad. de Emma Calatayud). Aunque la idea de Yourcenar se refiere a la forma en que el paso del tiempo y las modificaciones congénitas a toda sociedad modifican la belleza de los objetos del pasado. Estos padecen a su manera lo equivalente al cansancio, las sevicias, el envejecimiento o la desgracia. Igual que ocurre con nosotros.
}

imaginarlo todo, no solo a su personaje sino cualquiera de los detalles concurrentes en la vida de finales del siglo XVI, un biógrafo de Felipe González no requiere de esta imaginación para ubicarse. Es decir que en el primer caso hay una dificultad añadida al no conocimiento del personaje y se requiere de enormes conocimientos de historia, política, cultura, leyes, religión y geografía para poder comprender el alcance y la significación tanto de los hechos cotidianos como de los más excepcionales.

Philippe Lejeune ha popularizado una anécdota relacionada con Luis XVI que permite hacerse una idea de lo dicho. El monarca francés fue el primero, según Lejeune, en llevar un diario desde la edad de 11 años, donde anotaba sus ocupaciones oficiales, sus viajes y su costumbre de salir de caza. A lo largo de la semana fatal comprendida entre el 11 y el 14 de julio de 1789 anotaría sucesivamente Rien en su cuaderno. Es decir, nada. Imaginamos el estupor de algunos historiadores al comprobar la supuesta ceguera del monarca ante el tsunami político que se avecinaba. Pero no sería justo para él pues lo que decía con tan contundente palabra es que aquella semana Luis XVI no había salido a cazar, y tampoco había sucedido nada relevante entre los muros de Versalles. Ciertamente donde estaban sucediendo cosas importantes era en las calles de París. Pero hay que conocer la costumbre de los reyes de llevar un diario de caza, para dar el sentido justo y apropiado al célebre Rien de Luis XVI 5 .

El segundo patrón de objetividad parte precisamente del aspecto contrario, del conocimiento directo del objeto. En este caso, las posibilidades básicas son dos: el biógrafo se beneficia de él o bien no se beneficia; puede solicitar la colaboración del biografiado, la de su entorno, la de sus colaboradores, puede acceder a documentación inaccesible a otras personas, puede incluso someter su manuscrito a la lectura y aprobación de su personaje para que éste corrija o matice aquello que crea oportuno; o bien escribe su biografía distanciándose por alguna razón de su influencia. Es lo que a mí me ocurrió, inesperadamente, en relación a Francisco Umbral. Con él acordé un proyecto biográfico que muy pronto se deshizo debido a nuestra mutua incompatibilidad a la hora de definir sus límites y objetivos. Mientras Umbral veía la biografía como una caja de resonancia de su propia identidad como escritor, yo aspiraba a comprender los vacíos y contradicciones que observaba en las semblanzas biográficas disponibles (por poner un solo ejemplo era imposible concretar su segundo apellido o bien su lugar de nacimiento), deseando reconstruir su trayectoria a partir de una base fehaciente.

\footnotetext{
Lo analiza Philippe Lejeune en Le journal intime. Histoire et anthologie, en colaboración con Catherine Bogaert, Textuel, 2006, p. 77.
} 
No hubo acuerdo posible y la relación entre nosotros se enfrió hasta el punto de amenazarme el escritor con los tribunales si proseguía con mi proyecto ${ }^{6}$. Es evidente que ambos procedíamos de lugares muy distintos: él estaba acostumbrado en su literatura a cubrir y descubrir con deslumbrantes metáforas y una potencia introspectiva inédita en la literatura española una profunda experiencia de soledad y extrañamiento, mientras que mi formación permanecía seducida por la metodología empleada por los grandes investigadores, a los que siempre he leído con una inmensa admiración. Él era un autor incisivo y brillante que había logrado edificar un imperio de letra impresa a partir de cimientos vitales tambaleantes. No hay duda, a toro pasado, de que yo no era la persona que él necesitaba para escribir su hagiografía. Nuestras divergencias salieron a la luz muy pronto: Umbral manifestó en las dos largas conversaciones que mantuvimos en relación al proyecto un rechazo evidente a proporcionar cualquier dato, incluso un rechazo a la explicación en general, que hacía muy difícil fijar la cronología de su vida, sin la cual era imposible plantearse un proyecto de más largo alcance. Cargada de preguntas que solo obtenían respuestas evasivas -"a ti lo que te gusta es el social realismo, como a Delibes", me diría varias veces-, opté por buscarlas por mí misma. La prueba documental obtenida en Madrid sobre el lugar y fecha de su nacimiento fue el desencadenante de nuestra ruptura, del contexto de discordia que ya se impuso entre nosotros hasta el final del proyecto y de su vida, unos años después. Ambos comprendimos que la colaboración se había vuelto imposible: la mera obtención de su partida de nacimiento era un hecho que hablaba por sí mismo, generaba hipótesis que impugnaban las múltiples versiones que él había dicho y escrito sobre su infancia, iluminándolas bajo una nueva luz. Umbral había disuelto el hecho de haber nacido en la Inclusa como hijo de madre soltera (y lo que esta situación dramática trajo consigo) en una escritura literaria indiscernible de la ficción, al tiempo que en una fijación permanente. Un espacio proteico, presto tanto a la contención como al desbordamiento. Un espacio sobrepasado por el dolor. Era algo que me había llamado poderosamente la atención en libros como Memorias de un niño de derechas, Los males sagrados, Mortal y rosa, Las ninfas, Diario de un escritor burgués, El hijo de Greta Garbo, La belleza convulsa, Los cuadernos de Luis Vives... Así, leyendo su obra, empezó todo. Conocer la dificultad de su origen permitía comprender el desfase afectivo y social que el escritor volcaba en sus libros y desencadenaba, forzosamente, una nueva interpretación,

\footnotetext{
6 El proceso de progresiva hostilidad que sufrió nuestra relación está expuesto en mi libro Francisco Umbral. El frio de una vida, Espasa, 2004.
}

ubicada en un traumático y absorbente autobiografismo. Esa fue la hipótesis de trabajo que seguiría. Al autor de Mortal y rosa, sin embargo, el procedimiento -que arrojaba un haz de sombras a la invención de su relato familiar- no le complació en absoluto: ¿quién era yo para saber lo que nadie sabía? Comprendo perfectamente su posición (siempre la comprendí), el impacto que debió de suponerle el verse confrontado con una memoria veraz hasta entonces instrumentalizada. Y creo que eso explica muy bien el sentimiento de amenaza en el que vivía el escritor; porque, en el fondo, la fragilidad de Umbral era extrema. En todo caso, la vuelta atrás era imposible. ¿Podía restaurarse la confianza mutua? La respuesta es que no. A partir de ese hallazgo sobre el cual escribí un primer artículo ${ }^{7}$, busqué en otras fuentes el eco de su voz, exhumé las huellas de sus pasos hasta donde me fue posible. Umbral había construido una ficción de la realidad vivida y la había hecho su verdad, presentándola como tal indiscriminadamente (es decir, aplicable tanto en un registro creativo como historiográfico y supuestamente veraz (la entrada de un diccionario literario, por ejemplo). Mi pregunta es: ¿yo debía aceptarla sin más? De responder afirmativamente, ¿cuál es entonces el papel de un biógrafo? ¿Obviar las dificultades? ¿Convertirse en un mero altavoz acrítico de los deseos del biografiado sobre sí mismo? Un biógrafo en realidad no escribe la vida de nadie; sencillamente, la deja hablar. Su objetivo tampoco es solventar las asperezas de la existencia, sino detenerse en analizarlas, cuando menos reparar en ellas y en su significación y alcance existencial. He aquí el choque que se produjo entre mi conciencia y la suya. Mi deber de memoria y su necesidad de olvido, por decirlo en términos de Paul Ricoeur. ¿Hice bien, hice mal? Sobre El frío de una vida cayó en su momento un plúmbeo silencio. A su alrededor se hizo un vacío espectacular. El libro, para mi sorpresa, no generó el menor debate, nada de su contenido se discutió, y sigue sin discutirse (aunque nunca diría que el efecto de la publicación sobre la escritura de Umbral fuera nulo). El problema, una vez más, no fue de orden objetivo sino subjetivo. Y hay que aceptarlo porque cada uno se juega su destino en los riesgos que asume.

Lo que quiero decir es que cualquiera de los dos patrones encierran una parecida complejidad. Es posible que en un primer momento resulte más fácil pensar que disponer del testimonio directo del biografiado facilita las cosas, pero muy pronto se comprende que surgen otro tipo de dificultades de orden moral o deontológico que deberán afrontarse.

La epistemología de la biografía exige que el conocimiento del personaje arranque de lo que ya se sabe

"Francisco Umbral: los comienzos de un escritor", Boletín de la Unidad 
sobre él, ya sea para ir más lejos o en otra dirección, pero, en todo caso, el punto de partida del biógrafo no es tanto el propio personaje sino el conocimiento que se tiene sobre él en el momento de iniciarse la investigación. A no ser que se trate de una "biografía de autor" donde tan relevante es la trayectoria del personaje como la mirada creativa del biógrafo ocasional aplicada sobre el mismo. La escritora Nuria Amat dirigió una colección titulada "Vidas literarias", un total de 26 biografías publicadas por Omega, entre 2001 y 2005 (aunque el número es aproximado, no dispongo de los datos exactos), concebida bajo esa perspectiva: la colección aspiraba a ofrecer biografías (no muy extensas) de escritores encargadas a su vez a otros escritores, en su mayoría reconocidos, bajo la premisa de ofrecer una "mirada de autor" sobre el biografiado. Eso significa que en este caso el proyecto literario es doble, en la medida que tanto nos puede interesar el conocimiento biográfico del autor seleccionado como el punto de vista elegido por el biógrafo para presentarlo. Por las mismas fechas aparecía en Espasa otra colección titulada "Vidas de escritores", dirigida por mí misma y que aspiraba a recuperar el espíritu de un importante proyecto promovido por Ortega y Gasset, entre 1929 y 1942, titulado Vidas españolas e hispanoamericanas del siglo XIX, dirigido por Melchor Fernández Almagro. La falta de biografías ágiles, útiles y escritas con el utillaje metodológico y crítico propio de nuestra época, de los escritores de habla hispana, fue el motivo que impulsó el deseo de proseguir con el proyecto orteguiano. Sin embargo, ninguna de las dos colecciones tuvo el éxito de público suficiente, mostrando una evidente falta de tradición biográfica en relación a los escritores autóctonos. El desentendimiento de quiénes han sido nuestros escritores, tanto entre el público lector como por parte de estudiosos y críticos, ha sido mayúsculo hasta fechas recientes. Todo el interés se ha venido centrando en la obra y en la ideología, dejando en la mayor oscuridad su vida como creadores, sus intenciones y la interpretación que ellos mismos insistieron en ofrecer de su obra literaria, depositada mayoritariamente en sus diarios y correspondencias, escrituras tan poco exploradas hasta el cambio de paradigma que supuso la emergencia de las literaturas del Yo en los años 80 del pasado siglo. Sin embargo, diarios y correspondencias son piezas imprescindibles - lo han sido hasta el cambio de siglo, cuando las nuevas tecnologías van a requerir de nuevas metodologías biográficas en el futuro inmediato. Como he dicho en numerosas ocasiones, en la cultura española no solo se ha venido haciendo todo lo posible por marginar el conocimiento biográfico vinculado a la intimidad de los creadores sino que muy a menudo se alardeó de la destrucción de papeles personales alegando su carácter indiscreto. Como señala Francisco Pérez
Gutiérrez $^{8}$, quienes así han actuado en nombre de una supuesta honorabilidad no solo han comprometido la veracidad de una posible escritura biográfica sino la autenticidad de la obra literaria, la posibilidad de que esta se leyera de acuerdo con las intenciones y el sentido que su autor quería darle: la pérdida de una carta, de un diario, de un testimonio personal no solo borra definitivamente un momento en la vida de un artista, como dice Pérez Gutiérrez, sino que puede oscurecer de forma igualmente definitiva el sentido de una página, la historia de una idea, el arranque de una inspiración, la posibilidad de una empatía histórica que solo el conocimiento biográfico ofrece.

\section{2}

El horizonte intelectual de la biografía no tiene fin, como no lo tiene ningún horizonte humanista. Nuestro objetivo no es identificar un nuevo virus o descubrir las leyes que gobiernan los genes. Nuestro objetivo es comprender el pasado en una dimensión lo más compleja posible, reconstruirlo a partir de las múltiples huellas disponibles (a pesar de la destrucción) y eso es una tarea siempre revisable. Tal vez esta sea la diferencia esencial en relación a la escritura estrictamente creativa, una diferencia señalada de forma pionera por Virginia Woolf. Una obra de ficción no es susceptible de mejora, permanece en su singularidad sin que otros relatos puedan desdecirla. Por el contrario, la escritura biográfica es una escritura histórica basada en la interpretación de hechos $\mathrm{y}$ experiencias que sucedieron $\mathrm{y}$, en este sentido, es ampliamente revisable. El tiempo juega a favor de toda escritura histórica, matizando, corrigiendo, corroborando, en el mejor de los casos, con nuevas y tal vez inéditas aportaciones lo escrito en el pasado. Por ello no me parece adecuado hablar de biografías definitivas, cuando el conocimiento de una vida humana nunca lo es, ni puede serlo. Bastó que un arrogante Geoffrey Parker permitiera que la editorial titulara su última versión de la biografía de Felipe II, Felipe II: la biografía definitiva (Planeta, 2010) para que algunos historiadores españoles señalaran humanísimos vacíos. "Todas las empresas históricas son en realidad un trabajo en curso, una obra que constituye una forma de colaboración a través de generaciones" escribe sir John H. Elliot en Haciendo historia, un comentario que parece un toque de atención avant la lettre a su aventajado discípulo. Me parece una buena forma de definir el trabajo biográfico, una forma de colaboración entre generaciones que parte de reconocer

\footnotetext{
8 En El problema religioso en la Generación de 1868. "La leyenda de Dios". Valera, Alarcón, Pereda, Pérez Galdós, Clarin, Bardo Bazán, Taurus, 1975, p. 14.
} 
las aportaciones anteriores y confiar en poder superarlas por una mejor interpretación de sus condicionantes históricos, psicológicos, políticos o culturales.

A esa ambición de totalidad que solo puede ser un horizonte de expectativas para el biógrafo, yo la llamaría el "paradigma James Boswell", el autor de la magnífica biografía dedicada a Samuel Johnson, Life of Samuel Johnson (1791) elaborada después de cientos de horas de conversación, de experiencias compartidas entre ambos, de cartas cruzadas con los amigos de Johnson y de acceder Boswell al archivo del filólogo, mostrando los claroscuros del personaje, sin por ello dejar de sentir una inmensa admiración por el personaje. En la obra de Boswell hay un afán de totalidad que es sin duda la aspiración de cualquier biógrafo y que molestó extraordinariamente en su tiempo, cuando los contemporáneos que admiraban al maestro Johnson consideraron que presentarlo como un hombre con severos defectos no solo no era necesario sino que solo podía haberlo cometido un ser estúpido e irresponsable.

Es evidente que solo quien se halle en el segundo apartado al que nos referimos, es decir que pueda disponer de un conocimiento directo del personaje, está en disposición de satisfacer la curiosidad expuesta por Higshmith: conocer las particularidades físicas y privadas que rodean la vida material y por supuesto la gestación de una obra de arte. Un artista como Salvador Dalí haría de esta curiosidad, un punto obscena por el genio, una actuación permanente.

Ahora bien, ¿qué relevancia puede tener la forma en que Shakespeare encorvaba la espalda al escribir a la hora de preparar una biografía del dramaturgo? La respuesta es que hay muchas formas de describir la personalidad y ciertamente la que más puede interesar a un biógrafo es la que procede de un conocimiento directo, íntimo, en el sentido de haber podido acceder a lo que, por lo general, permanece oculto a la observación pública porque esta suele recibir al personaje ya hecho para la ocasión, pertrechado de seguridades que tal vez no posee. Ya lo dijo Plutarco al comienzo a su biografía de Alejandro Magno (superior, por cierto a la de su paralelo, Julio César, porque Plutarco era griego, vivió en Alejandría - la urbe fundada por Alejandro en honor de Homero y dotada de la biblioteca más importante del mundo y su conocimiento del personaje revela una profundidad que el de Julio César no tiene). Bien, dice Plutarco que los detalles más insignificantes son con frecuencia los más interesantes, pues la biografía no aspira a escribir la historia sino una experiencia humana, una concreta, singularizada por las muchas influencias que condicionaron su discurrir: "mi propósito no es escribir historias, sino vidas". Esa mezcla de destino, azar y carácter de la que hablaría Ortega siglos más tarde y que en cada vida humana cristaliza de una forma singular a la que el biógrafo debe acercarse con la voluntad de alcanzar alguna forma sistemática.

Podríamos afirmar que sólo en el caso del conocimiento directo del personaje se produce la experiencia del conocer de la que hablaba el psicólogo William James y que yo misma pude comprobar en mis dos biografías escritas hasta la fecha. Al escritor Francisco Umbral le conocí, le traté en varias entrevistas que tuvimos, almorcé con él en varias ocasiones. Es un conocimiento incomparable a la hora de escribir: uno puede imaginarse al personaje, sabe cómo se mueve, cómo anda, cómo entona la voz o cómo reverberan sus palabras. Dispone, en fin, de esa aproximación a la que se refiere Higsmith y que tiene un valor incalculable. Por el contrario, apenas vi en una ocasión y de forma muy distante a Carmen Laforet y me costó mucho imaginarla en su vida cotidiana. Por ello no entiendo que alguien pueda desdeñar ese conocimiento, a no ser que el biógrafo ya tenga una idea preconcebida del personaje y se proponga demostrarla. O bien, que ya conociéndolo previamente mantenga su investigación al margen a fin de preservar su propia autonomía. La casuística biográfica es enorme y apasionante, aunque la biografía como género apenas ha merecido atención crítica y mucho menos teórica: lo señalaba el gran biógrafo de Henry James, Leon Edel, en una entrevista a The Paris Review ${ }^{9}$. Podría decirse que la biografía es el género más practicado y menos estudiado de la historiografía literaria, un rasgo propio de las escrituras consideradas como "naturales", del tipo de la autobiografía, el diario o las cartas, géneros fuertemente codificados retóricamente, con una carga ideológica o teleológica muy presente -son refractarios al concepto de obra abierta de Umberto Eco- y que por ello mismo han quedado excluidos de los estudios literarios. Supuestamente no son literatura.

Lo comprobamos muy a menudo en la crítica literaria, tanto la que se ejerce en los suplementos culturales y revistas especializadas como la desarrollada en el mundo académico. Ambos suelen centrarse en glosar o discutir el contenido de una biografía, los aspectos más o menos amarillistas de su vida despreocupándose del "artefacto" que la ha puesto en pie, de la compleja historia que se establece entre biógrafo y biografiado, de la legitimidad de sus fuentes o de su aportación en relación a otros trabajos biográficos anteriores. Y eso es porque el empeño epistemológico de la biografía, acceder a la interioridad del ser, desventrar su misterio, es una dificultad insuperable: la vida de un ser humano NO puede ser contada. Y pese a ello las biografías no dejan

\footnotetext{
9 "The Art of Biography", por Jeanne McCulloch, a propósito del libro de Edel, Writing Lives: Principia Biographica $(1984,1989),<\mathrm{https}: / / \mathrm{www}$. theparisreview.org/interviews/2844/leon-edel-the-art-of-biography-no1-leon-edel>.
} 
de sucederse. He aquí un obsesivo de naturaleza borgeana que define la naturaleza de su empeño. En todo caso, es en los procedimientos del biógrafo en lo que debe reparar la crítica a la hora de valorar la calidad de una biografía.

En 1993 la revista Letra Internacional dedicó un monográfico a los géneros de la memoria desde una perspectiva teórica. Lo titularon "Vidas narradas" y en él colaboraba el estadounidense Leon Edel, ya mencionado, con un artículo titulado "La nueva biografía" en el que enumeraba varios de los puntos que definían la revolución de Lytton Strachey, insistiendo en la importancia que tuvo el psicoanálisis en la evolución del género y en la necesidad de que el biógrafo reconstruyera "la mitología privada del individuo" que biografiaba. Pero el último párrafo del artículo de Edel era desmoralizador:

Lamento decir que no existe una crítica biográfica que merezca esa denominación". Si esa crítica existiera, debería poder responder a una serie de preguntas: “¿Cómo ha distinguido el biógrafo entre sus testigos confiables y aquellos que no lo son? ¿Cómo ha evitado convertirse simplemente en la voz del sujeto sobre el que escribe? ¿Cómo ha relatado su historia? En cuanto a la información presentada ¿queda justificada en la narración?

Etc. Etc. Son preguntas, pueden añadirse algunas más, como ¿hay coherencia entre los presupuestos que se manejan y la persona real que los encarnó?, que Edel se formula porque sabe muy bien cuáles son las dificultades de escribir una biografía. Inquiere sobre cuestiones que fundamentan su modo de trabajo: la fiabilidad de las fuentes, la objetividad del biógrafo, la coherencia del punto de vista adoptado y cómo ha organizado el material en una macroestructura narrativa que solo puede ofrecer una parva selección e interpretación de los hechos considerados fundamentales. "Hasta el momento, concluye Edel, la biografía ha sido un arte muy poco consciente de sí mismo". Es así, lo era en 1993 y sigue siendo así, aunque cada vez el mundo académico se interesa más por la teoría del género planteándose los retos de su escritura desde un nivel reflexivo muy superior. Sin embargo, la mayor parte de los debates que giran en torno a la biografía se centran en cuestiones vinculadas a la legitimación del proyecto biográfico y su relación con la ficción, no tanto sobre las cuestiones epistemológicas que son las que finalmente deciden la calidad de un texto. Se escriben historias externas del género, la crítica suele glosar el contenido de las aportaciones vertidas en una biografía, los propios biógrafos se glosan a sí mismos hablando de sus personajes, pero muy pocos, en fin, se detienen en lo esencial: el análisis de los avances metodológicos que se han hecho. Por poner un ejemplo, si existiera esa crítica que algunos ejercemos con el mayor voluntarismo y cierta soledad no habría pasado desapercibido en el mundo cultural catalán un libro tan importante para el género como la Crònica de la vida d'Agustí Bartra, escrito por su mujer, la también escritora Anna Murià y que participa plenamente del espíritu boswelliano del que hablábamos más arriba. Su autora presentó el libro al premio Aedos de Biografías, fundado por la editorial Selecta en $1953^{10}$, un premio que supuso un impulso decisivo en el desarrollo de la escritura biográfica en Cataluña, con aportaciones tan valiosas como la biografía del poeta Jacint Verdaguer escrita por Sebastián Juan Arbó, nunca estudiada desde el punto de vista del género. El libro de Murià, en todo caso, fue rechazado en la convocatoria de1966 por no acogerse a las bases del premio, que exigían que el personaje hubiera fallecido. Reproduzco el comentario de Murià en una carta a su hija Eli, días después de recibir la noticia:

La Crónica no será premiada porque hay una cláusula en la cual se requiere que el biografiado esté muerto.

Esperaba la derrota, pero no ésta. Es como si me hubiera vencido el cementerio. No esperaba esa tristeza tan profunda y tan amarga que me produjo la noticia. Catalunya no quiere vivos, quiere muertos ${ }^{11}$.

\section{3}

Escribir una biografía es un ejercicio inductivo, que nos obliga a extraer del contexto, de la experiencia colectiva en la que está inmerso el individuo, de la conducta humana en general, valiosas lecciones aplicables al caso concreto y, al mismo tiempo, es un ejercicio deductivo porque obliga a trabajar con las "estructuras supervivientes" (utilizo la expresión de Gaddis en Paisajes de la historia) que ha dejado una persona singular y de las que forzosamente el biógrafo extrae conclusiones que van más allá del hecho singular y permiten dibujar una personalidad, los rasgos de una conducta. Si el biógrafo ha tenido acceso directo al personaje como veíamos antes, accede a un patrón de objetividad inaccesible en el resto de los casos. Pero ninguno de los dos procedimientos, el inductivo y el deductivo, pueden imponerse demasiado sobre el otro.

Si en una biografía domina la inducción nos encontramos ante una biografía generacional, o intelectual o acorde con la historia social que utiliza el individuo para mostrar una clase, un movimiento o un acontecimiento. Es el tipo de biografía que ha escrito Christopher Domínguez en relación a Octavio Paz, y el título de su obra no engaña: Octavio Paz en su siglo.

\footnotetext{
${ }^{10}$ A día de hoy sigue pendiente el estudio de tan importante catálogo editorial.

11 Carta del 6/12/1966, inédita, citada por Sam Abrams en su prólogo a la traducción al castellano de la obra, "Anna Murià y su Crónica de la vida de Agusti Bartra”, editada por el FCE, 2013, p. 15-16. Traducción de Maiala Meza. Escribí un trabajo sobre este libro: ¿Dónde está el hogar? Autobiografía y exilio, en Cuadernos del CILHA < cuadernosdelcilha. uncu.edu.ar>
} 
También es el procedimiento verdaderamente innovador manejado por Christopher Blom en su Enciclopedia o en Años de vértigo, o Rüdiger Safranski en Romanticismo, estudios de historia o de filosofía que recurren a la biografía de sus protagonistas como una especie de hilo conductor que afianza sólidamente el relato. Unos pocos detalles se utilizan sabiamente para armar el relato del nacimiento de la filosofía alemana. Si por el contrario, la biografía recurre principalmente a la deducción, quizás porque posee suficientes materiales del personaje como para no tener que pensar en nada más, se corre el riesgo de incurrir en un relato atomizado, casuístico, tal vez cargado de información precisa y erudita, pero ausente de una síntesis iluminadora e interpretativa.

Pido disculpas por estas consideraciones tan obvias. Pero resulta difícil valorar la biografía sin ubicar el análisis en el marco teórico que yo misma manejo. Confieso que para mí la reflexión teórica sobre la biografía no ha precedido sino que ha surgido de una práctica que me ha obligado a reflexionar sobre ella. Práctica en un doble sentido: dedicándome a la crítica regular de la biografía en un suplemento cultural de alcance nacional, por un lado y yo misma escribiendo biografías de escritores por el otro. Y también he llegado a la conclusión de Leon Edel, de que apenas existe una teoría biográfica y al carecer de una escuela, lo que ha dominado en el ámbito hispánico ha sido una especie de adanismo y recojo la definición del DRAE que lo define como "Tendencia a comenzar una actividad sin tener en cuenta los progresos que se hayan hecho anteriormente". Todavía un intelectual de la talla de Luis Racionero, al presentar el segundo premio de biografías Stella Maris (un proyecto que se deshizo como el humo, apenas tres convocatorias, entre 2015 y 2017 , y cerró) afirmaba que “el género biográfico en España no cuenta con ningún predicamento"12, cuando lo cierto es que el interés y la producción se han incrementado mucho, enormemente. ¿Qué hay que hacer para que los intelectuales instalados en los medios culturales cambien sus inercias y dejen de repetir una vez y otra situaciones que ya están superadas? La situación ha cambiado mucho en los últimos años con un interés creciente. Lo señalaba Jorge Herralde, fundador y editor de Anagrama, refiriéndose a la traducción al castellano de dos biografías importantes: la de Richard Ellman sobre James Joyce apareció en 1991 y fue "uno de los mayores fiascos de mi vida como editor". Y, sigue Herralde, lo mismo sucedió con el primer volumen de la biografía de Brian Boyd sobre Nabokov, Los años rusos, 2006). Las pocas ventas llevaron al editor a cerrar su Biblioteca de la Memoria, inaugurada con la publicación al castellano de la biografía de Giangiacomo Feltrinelli,

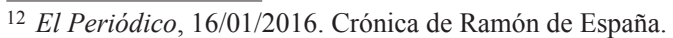

escrita por su hijo Carlo (Senior Service. Biografía de un editor $)^{13}$.

\section{4}

Avancemos. La anterior afirmación de Edel, referida al medio anglosajón donde la biografía ha sido y sigue siendo una herramienta cultural de primera magnitud (en Gran Bretaña hay más de 80 universidades que cuentan con la especialidad de la escritura biográfica en sus estudios) adquiere inusitada fuerza en la cultura hispánica, cruzada por una inveterada falta de libertad moral, política y expresiva, donde biografías y autobiografías se vieron sometidas a la ortodoxia católica más asfixiante. Ortega y Gasset es en este sentido una referencia indiscutible, pues él hizo lo imposible en los años 20 del pasado siglo por generar una escuela biográfica española: denunció nuestro vacío, creó una valiosa colección de "Vidas españolas e hispanoamericanas", antes citada, y en la que puso a trabajar a todo el círculo de la Revista de Occidente -Benjamín Jarnés, Antonio de Marichalar, Antonio Espina (indudablemente el mejor biógrafo del grupo ${ }^{14}$ ), ..-, y apoyó el género desde una perspectiva filosófica con su defensa de la razón vital, que después pensadoras como María Zambrano y Rosa Chacel adaptarían a su modo.

El franquismo vendría a alterar la significación concedida en los años anteriores a la biografía, sofocando aquella incipiente e innovadora escuela que dio frutos tan innovadores como la Vida de Manolo de Josep Pla, la Vida de Juan Belmonte de Chaves Nogales o Teresa de Rosa Chacel, sobre la amante de Espronceda, Teresa Mancha. A raíz de la victoria del bando nacional o franquista, en 1939, el género sería utilizado como una herramienta más de formación de un nuevo espíritu nacional, basado en unos determinados ideales (cristianismo, antifeminismo, valor, patriotismo español, rechazo a los valores del mundo moderno y exaltación del pasado imperial). La eficacia pedagógica y ejemplarizante del género biográfico era ya indiscutible para Plutarco y así fue como el género se convirtió, en palabras de Jordi Amat, en crisol ideológico del nacionalcatolicismo que aspiraba a enlazar la nueva etapa política surgida de la derrota republicana con los orígenes del imperio español ${ }^{15}$. "Éramos contemporáneos de los Reyes Católicos" afirmaba Josep Pla refiriéndose al clima moral regresivo de la primera postguerra, aquel cotidiano anacronismo de cartón piedra sobre el que giraba la educación y el lenguaje. El objetivo político del franquismo constituyó en sí mismo un enorme fracaso, pues

\footnotetext{
${ }_{13}$ Declaraciones de Jorge Herralde a la autora del articulo, abril de 2017.

14 Jordi Amat le dedicó un magnifico articulo: "Antonio Espina, "nuevo biógrafo": Cervantes (1943), en Memoria. Revista de Estudios Biográficos, n. 3, p. 4-15, 2007.

${ }^{15}$ En el mismo artículo, p. 11.
} 
el proyecto de conseguir una resurrección de determinado pasado nacional, enfrentándolo beligerantemente a otro de carácter progresista y liberal, chocaba con la ampulosidad y la falta de verdad que lo sustentaba, y eso mismo lo hizo inviable. Pero en una primera etapa, la hegemonía ideológica del franquismo, basada en el miedo y la persecución de los vencidos, fue absoluta. Fueron también los años de más vitalidad en la producción de una biografía ideologizada: los relatos servían para exaltar el heroísmo y la ejemplaridad cristiana de personajes cuyas trayectorias se ajustaban al perfil intelectualmente escolástico requerido por el régimen franquista: el Cid, los Reyes Católicos, Teresa de Jesús, Genoveva de Brabante, Agustina de Aragón, Guzmán el Bueno, Cisneros, conquistadores de la talla de Cortés o Pizarro, Felipe II, ... El resultado fue una historia de España concebida como una galería de mitos nacionales. Y en esa articulación del discurso histórico-ideológico en torno a algunas figuras heroicas la significación alcanzada por Felipe II merecería un capítulo aparte. Sin duda es, viene siendo, el epicentro histórico de la escritura biográfica española, pues de ningún otro monarca o personaje histórico se tiene tanta información y ha generado tan voluminosa bibliografía.

En todo caso, el rechazo moral que provocó el género biográfico debido a la manipulación ideológica sufrida durante el franquismo tendría a la larga efectos devastadores. Podría decirse que a ese rechazo se sumó en los años ochenta el auge del estructuralismo francés o del close reading propugnado por la escuela de Chicago, por no hablar de las corrientes historiográficas que marginarían la aportación del individuo en beneficio del grupo social o del texto muy por encima de su autor. Corrientes que reivindicaban la autonomía literaria o la importancia de la historia social frente a los parerga y paralipómena, por decirlo con Schopenhauer, es decir frente a todo aquello que podía constituir el entorno de un texto y no la escritura en sí. Una situación que se mantuvo hasta que la necesidad de recuperar la memoria de figuras histórico-políticas que habían permanecido olvidadas y/o silenciadas activó de nuevo la escritura biográfica vinculándola, sin embargo, más a la historia que a la literatura.

Lo que quiero decir es que no hemos estudiado lo suficiente nuestra tradición biográfica pues esta ha sido constantemente interrumpida y se ha visto como inexistente, sin serlo. Ya todos sabemos por qué, pero lo importante, lo que me interesaría subrayar aquí es que en las últimas décadas estamos logrando crear un espacio biográfico inédito que se inspira fundamentalmente en modelos ajenos pero que, en todo caso, representa un hilo de continuidad en relación a aquella escuela biográfica con la que soñó Ortega en la década de los 20 y que de tener algo más de recorrido hubiera sido fundamental. Ahora el intento, real, topa con el problema de rebajar la beligerancia en relación a los personajes, en su mayor parte objetos de enconadas polémicas. ¿Cómo lograr una suerte de naturalidad a la hora de abordar el relato biográfico? He aquí el principal desafío.

\section{Referencias}

AMAT, Jordi. Antonio Espina, "nuevo biógrafo": Cervantes (1943). In: Memoria - Revista de Estudios Biográficos, n. 3, p. 4-15, 2007.

CABALLÉ, Anna. Francisco Umbral: los comienzos de un escritor. Boletín de la Unidad de Estudios Biográficos, Universitat de Barcelona, n. 4, p. 9-20, 1999.

CABALLÉ, Anna. Francisco Umbral. El frío de una vida. Espasa, 2004.

CABALLÉ, Anna. ¿Dónde está el hogar? Autobiografía y exilio. In: Cuadernos del CILHA, Mendoza, v. 18, n. 2, jul. 2017.

EDEL, León. Writing Lives: Principia Biographica (1984, 1989). [En español: Vidas ajenas: Principia Biographica. Trad. de Evangelina Nuño. México: FCE, 1990].

LEJEUNE, Philippe (en colaboración con Catherine Bogaert). Le journal intime. Histoire et anthologie. Paris: Textuel, 2006.

MARTÍN GAITE, Carmen, El proceso de Macanaz. Historia de un empapelamiento. Madrid: Espasa Calpe, 1999.

MCCULLOCH, Jeanne. Leon Edel: The art of biography No. 1. Paris Review, Issue 98, Winter 1985. <https://www. theparisreview.org/interviews/2844/leon-edel-the-art-ofbiography-no-1-leon-edel>.

MURIÀ, Anna. Crónica de la vida de Agustí Bartra (1967). Trad. de Maiala Meza. México: FCE, 2013.

PÉREZ GUTIÉRREZ, Francisco. El problema religioso en la Generación de 1868. "La leyenda de Dios". Valera, Alarcón, Pereda, Pérez Galdós, Clarín, Bardo Bazán. Madrid: Taurus, 1975.

SHENKAR, Joan, The Talented Miss Highsmith. The secret life and serious art of Patricia Highsmith.New York: St. Martin's Press, 2009. [En español: Patricia Highsmith: biografía definitiva. Trad. de Clara Ministral. Barcelona: Circe, 2010].

TERUEL, José (Ed.). Carmen Martín Gaite/Juan Benet. Correspondencia. Barcelona: Galaxia Gutenberg, 2011.

YOURCENAR, Marguerite. El tiempo, gran escultor (1983). Trad. de Emma Calatayud. Madrid: Alfaguara, 1989.

Recebido: $16 / 04 / 2018$

Aprovado: 20/04/2018

Contato:

Anna Caballé <annacaballem@gmail.com>

ORCID: https://orcid.org/0000-0002-3508-8474 